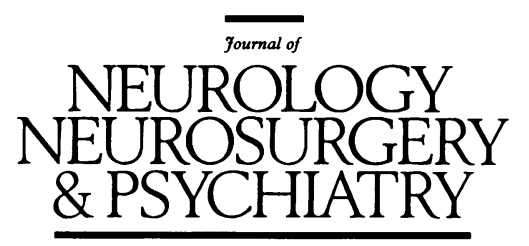

\title{
Editorial
}

\section{The motor disorder of multiple system atrophy}

The term multiple system atrophy was originally proposed by Graham and Oppenheimer ${ }^{1}$ in a paper describing a patient with autonomic failure, cerebellar ataxia and probable pyramidal signs, but no parkinsonism, in life. Pathologically, there was cell loss and gliosis, without Lewy bodies, not only in intermediolateral cell columns, olives, pons and cerebellum, but also in the substantia nigra and the putamen. The term then was developed ${ }^{2}$ as a common label to include many, but not all, cases of idiopathic orthostatic hypotension, ${ }^{3}$ or pure autonomic failure (others may have Lewy body disease), Shy-Drager syndrome ${ }^{4}$ and autonomic failure associated with olivopontocerebellar atrophy (OPCA), ${ }^{5}$ and striatonigral degeneration. ${ }^{6}$ At autopsy, these cases showed involvement of most or all of the above structures to varying degrees..$^{78}$ Some authors subsequently sought to widen the usage of the term to include other degenerative brain diseases. MSA is a specific condition, however, and only one of a number of "multisystem degenerations". Oppenheimer was willing to consider that MSA may also be familial and, indeed, the pathology of dominantly inherited OPCA could often be difficult to distinguish from that of some cases of sporadic cerebellar-predominant MSA. Clinically, however, there are often important differences. Thus, in some familial cases, pigmentary retinopathy, optic atrophy or dementia, ${ }^{9}$ and in some others titubation, supranuclear ophthalmoplegia including downgaze, areflexia or cataracts, ${ }^{10}$ which are not part of sporadic MSA, may be seen. Another difference is the usual absence of autonomic failure and the generally younger onset and often much longer survival of familial cases of OPCA. The most convincing argument for considering sporadic adult-onset cases of striatonigral degeneration, Shy-Drager syndrome, and OPCA as suffering with one disorder, namely MSA (which is, moreover, distinct from familial OPCA) comes from the recent independent demonstration in such cases by several groups of oligodendroglial ${ }^{11-15}$ and neuronal ${ }^{15-17}$ intracytoplasmic and intranuclear inclusions, which have not been found in 15 cases of familial OPCA, nor in a large number of neurological controls including idiopathic Parkinson's disease and Steele-Richardson-Olszewski disease. They have been found in one atypical patient (age at onset 52 years, age at death 56 years) said to have familial OPCA. Clinical diagnostic criteria for possible, probable and definite MSA as a sporadic disease with onset above age 30 years have been proposed ${ }^{18}$ and, more recently, slightly revised with the addition of proposed pathological criteria. ${ }^{19}$
Two approaches to characterising the motor disorder of MSA are possible. A prospective study of patients diagnosed in life as MSA should give good clinical data, but might involve some degree of diagnostic uncertainty. An alternative approach is to attempt to build up a clinical picture of the disease from pathologically confirmed cases. For this review, we have chosen the second method. Thus, the data we present here are based upon 188 cases of pathologically proven MSA $^{19}$ (sporadic adult-onset cases showing striatonigral or olivopontocerebellar atrophy at autopsy, or both - reference list available from the authors on request) for whom reasonable information on the presence or absence of key clinical features was available. We recognise, however, that insistence on pathological verification necessarily limits the clinical information available, just as prospective clinical studies may be criticised for the lack of pathology.

The major elements of the motor disorder of MSA were, first and foremost, parkinsonism (89\%), followed by cerebellar signs $(56 \%)$ and pyramidal signs $(62.5 \%)$. It might generally be considered easy to decide whether or not a patient has parkinsonism, a cerebellar syndrome, or pyramidal signs, and indeed when each is seen in isolation this is usually the case. Problems arise, however, when, as in MSA, more than one motor system may be affected.

\section{Parkinsonism}

Some features of parkinsonism were noted at some time in life in $89 \%$ of cases. Of all the 167 patients with parkinsonism, $60 \%$ had additional pyramidal signs, $50 \%$ cerebellar signs, and $35 \%$ both; $26 \%$ had only parkinsonism and pyramidal signs and $15.5 \%$ only parkinsonism and cerebellar signs. Features of autonomic failure were recorded in only $77 \%$ of all the MSA cases with parkinsonism, but our own clinical experience suggests that some degree of autonomic disturbance can be elicited by careful history-taking in virtually all patients with MSA.

A quarter $(24 \%)$ of the patients with parkinsonism had neither pyramidal nor cerebellar signs. In these patients the clinical semiology alone could be compatible with either Lewy body (idiopathic) Parkinson's disease or MSA, and indeed the differentiation between these two entities is the most common diagnostic problem. Idiopathic Parkinson's disease most commonly begins unilaterally, remains asymmetric, and a classic resting tremor is present in most cases. A symmetrical akineticrigid picture is not uncommon, however, particularly 
among younger patients. It is also often supposed that MSA, which appears on average to start somewhat younger than idiopathic Parkinson's disease is a symmetrical disease in which rest tremor is not seen. MSA can be very assymetric, however, and tremor at rest also can occur, although a classic parkinsonian pill-rolling rest tremor is uncommon. Certainly there are group differences in the frequencies of these patterns of parkinsonism in idiopathic Parkinson's disease and MSA, but in the individual patient they can only be weighted together with other more important diagnostic pointers-for example, the presence of cerebellar and true pyramidal signs, which are not part of idiopathic Parkinson's disease. $^{20}$

Parkinsonism is often easily identified when tremor is present. Early akinesia and rigidity, however, can often go unrecognised for years. On the one hand, ataxia can mask akinesia. On the other, patients who are unsteady from whatever cause fail to swing their arms on walking.

Patients with idiopathic Parkinson's disease show both nigral cell loss and substantial clinical benefit from levodopa. Some degree of nigral pathology, not always clinically eloquent, is almost invariably present in MSA. The levodopa response of patients with MSA, however, is usually poor or lacking. The simplest explanation may be loss of postsynaptic dopamine $\mathrm{D}_{2}$-receptors on striatal neurons. PET studies with ${ }^{11} \mathrm{C}$-raclopride have shown, however, that striatal postsynaptic $\mathrm{D}_{2}$-receptor binding is not much less in clinically diagnosed MSA than in patients with idiopathic Parkinson's disease who were treated chronically with levodopa. ${ }^{21}$ The problem must therefore lie in a disturbance of the non-dopaminergic intrastriatal neuronal machinery or striatopallidal systems, or of the motor systems outside the basal ganglia and, indeed, a recent PET study ${ }^{22}$ has demonstrated a striking loss of ${ }^{11} \mathrm{C}$-diprenorphine binding sites in the putamen of some subjects with MSA (including one OPCA-type case with autonomic failure but no clinical parkinsonism).

\section{Cerebellar signs}

Potential for confusion exists also when, less frequently, the initial presentation is largely cerebellar. Signs interpreted as cerebellar were noted in $56 \%$ of patients with MSA. They were present in $50 \%$ of the 167 cases with parkinsonism, but in $95 \%$ of the 21 cases without parkinsonism. When present, they were accompanied by pyramidal signs in $69 \%$.

Instead of the classical pill-rolling rest tremor, many patients with parkinsonism display a postural tremor which frequently worsens in the terminal position, and may also be present during action. Taken in isolation, this may be difficult to distinguish from a cerebellar intention tremor. One then looks for cerebellar signs elsewhere, but severe akinesia may mask dysmetria or dysdiadochokinesis.

Patients with MSA may speak with a typical slurring cerebellar dysarthria or the monotony and slightly low volume characteristic of idiopathic Parkinson's disease. Later, the voice may become severely hypophonic and assume a quivering, strained character and, in advanced MSA, speech may be all but lost, making it impossible to assess the nature of any dysarthria.

A pathological degree of square-wave jerks ${ }^{23}$ or the presence of nystagmus or ocular dysmetria may be helpful neuro-ophthalmologic pointers to cerebellar involvement.

Gait ataxia is the commonest cerebellar sign recognised in MSA. It is often possible, however, only to state that the patient is unsteady, without being able to grace the sign with the term "ataxia" as opposed to the postural instability of severe parkinsonism. These two components of gait impairment, locomotor ataxia (irregular timing, direction, and length of steps) and disequilibrium (loss of postural stability and compensatory postural reflexes) have different connotations. Locomotor ataxia, often with a wide base, implicates cerebellar pathology, and is not seen in idiopathic Parkinson's disease. Disequilibrium occurs in the late stages of idiopathic Parkinson's disease, in MSA and Steele-RichardsonOlszewski disease early in the course of the illness, and in frontal or midline cerebellar disturbances. Either or both may occur in MSA.

\section{Pyramidal signs}

Pyramidal signs were reported in $62.5 \%$ of patients with MSA. When present, they were accompanied by parkinsonian and cerebellar signs in $50 \%$, by parkinsonian signs alone in $37 \%$, and cerebellar signs alone in $12 \%$. In a single case $(0 \cdot 8 \%)$ the presence of pyramidal signs was the only motor feature accompanying autonomic failure in life.

In idiopathic Parkinson's disease, tendon reflexes are often relatively increased on the more affected side, and a spontaneously extensor toe of the "striatal foot" ${ }^{24}$ or the "dystonic foot response of parkinsonism" ${ }^{25}$ may be seen. Neither necessarily implies a pyramidal lesion. In our analysis we accepted as evidence of pyramidal signs the clear recording of extensor plantar responses, or the combination of hyper-reflexia and equivocal plantar responses. We have never ourselves observed a typical spastic gait.

Rigidity in idiopathic Parkinson's disease can usually be easily distinguished from spasticity, but where both may coexist in MSA they can be difficult to separate. Assessement of power in patients with marked akinesia and rigidity can be very misleading. What is initially labelled as a weak movement may, by dint of considerable encouragement and patience, produce a greatly delayed contraction of normal strength. Allowing for this, we have not actually encountered convincing pyramidal weakness in patients with MSA.

\section{Relationship of the motor disorder to the autonomic disorder}

Features of autonomic dysfunction commonly precede the first motor symptoms in MSA. In one specialised autonomic unit, Polinsky and $\mathrm{Nee}^{26}$ reported that in $75 \%$ of patients autonomic symptoms had appeared $4 \cdot 1$ (SD $0.5)$ years before the onset of motor symptoms. In the remaining $25 \%$, other neurological symptoms preceded autonomic ones by $2 \cdot 1(\mathrm{SD} 0 \cdot 3)$ years. In a retrospective case-note review of 32 patients with MSA in the UK Parkinson's Disease Society Brain Bank, however, first recorded symptoms were autonomic in $42.5 \%$. In parkinsonian or cerebellar clinics we probably see patients with a different presentation and evolution, and may not be as assiduous in extracting a prior or current history of autonomic disturbance.

Among those 167 patients with parkinsonism, some facet of autonomic dysfunction-namely, postural faintness, impotence, or urinary incontinence, had been recorded in $77 \%$, and in the 21 subjects without parkinsonism the frequency was $86 \%$. Autonomic symptoms were recorded in $87.5 \%$ of those with, and $65.5 \%$ of those without, cerebellar signs, and in $84.5 \%$ of those with, and $67 \%$ without, pyramidal signs. Every patient in 
whom autonomic dysfunction had been recorded had developed motor features before death in one (19\%), two $(44.5 \%)$ or three $(36.5 \%)$ domains (although one case of pure autonomic failure persisting to death due to MSA has since been reported). ${ }^{14}$ Among the subjects with "pure" parkinsonism the ratio of patients with, to those without, autonomic failure was $1 \cdot 1: 1$, but where both pyramidal and cerebellar signs were also present the ratio was $10 \cdot 6: 1$. This may signify a correlation between brainstem pathology and autonomic failure. Alternatively, autonomic symptoms may simply not have been noted in the absence of other atypical features.

Of all the cases with autonomic failure, $88 \%$ had parkinsonism, $67 \%$ had pyramidal signs, and $62 \%$ had cerebellar signs.

\section{Presentation and clinical course of patients with MSA and parkinsonism}

It is parkinsonism that most commonly brings the patient with MSA to medical attention, so most patients are initially diagnosed as, and treated for, idiopathic Parkinson's disease. The clues at presentation are often few and subtle. Moreover outpatients with parkinsonism usually undergo a full neurological examination only on their first visit, to be subsequently repeated only if they spontaneously complain of early falls, or postural faintness or blackouts, or fail to respond to levodopa, or are admitted to hospital.

At the first visit, tendon reflexes may be brisk, with either normal or equivocal plantar responses. The finding of extensor plantar responses is often put down to coincidental cervical spondylotic myelopathy, and sometimes myelography or spinal MRI is performed. Although there may be no tremor, or even a tremor at rest, it is more common to find a fine postural and action tremor. In many patients this may assume a rather irregular, jerky, character, and, on careful examination, some or all of it may be found to be due to discrete myoclonic jerks of the fingers which are often stretch-sensitive. ${ }^{27}$ Dementia $^{28}$ and seizures are not part of MSA, although glial $^{11-15}$ and neuronal ${ }^{15-17}$ inclusions can be found in both cortical and subcortical structures. Early gait instability is a useful clinical clue, and clear cerebellar signs at the initial consultation should strongly suggest the possibility of MSA.

Usually, subtle atypical features are not picked up early on, and levodopa treatment is soon instituted for presumed idiopathic Parkinson's disease. A poor or absent response to an adequate dose of levodopa given for an adequate period of time is frequent in MSA, although a moderate, or even a (usually transient) dramatic, response is seen in some patients. ${ }^{29} 30$ Thus the diagnosis is usually first questioned when the patient shows an atypical response to treatment. Much earlier in the disease the response to a single $250 \mathrm{mg}$ dose of levodopa (with a peripheral decarboxylase inhibitor) is a good (but imperfect) predictor of subsequent dopaminergic responsiveness, and is superior to the apomorphine test in this regard. ${ }^{31}$ The association of such challenge tests with iodobenzamide single positron emission $\mathrm{CT}^{32}$ or $1.5 \mathrm{~T} \mathrm{MRI}^{33}$ may prove useful in identifying "de-novo" patients with non-idiopathic disease. A pathological external urethral or anal sphincter EMG is also highly suggestive of MSA. ${ }^{34}$

Dopamine agonists are usually no more effective than levodopa in MSA, although some patients may tolerate them better. Anticholinergics must be used with due regard to the urinary status. We have found amantadine to be useful in some patients, perhaps because of downstream NMDA-receptor antagonist effects. Finally it is important to note that, particularly because of the absence of short-term fluctuations, many patients may appear to be deriving no benefit from their therapy, yet deteriorate alarmingly hours or days after stopping it. ${ }^{30}$

Patients with MSA often also lack typical, or display atypical, levodopa-induced dyskinesias on chronic levodopa treatment. Sustained dystonic spasms of facial muscles, ${ }^{30}$ particularly when unilateral, ${ }^{35}$ or predominantly torticollic movements, are often seen. The occurrence of dystonia in MSA as a feature of the disease itself, rather than as a consequence of treatment, is controversial. ${ }^{36}$ Some patients, usually late in the disease, develop a relatively fixed and disproportionate antecollis ${ }^{37}$ which often develops subacutely and may worsen throughout the day. This feature, however, is not pathognomonic of MSA. Distal contractures into fixed "dystonic" postures may occasionally be seen.

Whether major clinical involvement of anterior horn cells or somatic peripheral nerves is an integral part of the disease is controversial. Shy and Drager's original pathologically proven case 2 had neither fasciculations, nor atrophy, nor any loss of tendon reflexes, although the first two features were noted in their case 1 , for whom there was no pathology. ${ }^{4}$ Cohen et $a l^{38}$ found mild or asymptomatic distal sensorimotor polyneuropathy in seven of 36 patients diagnosed as MSA, with "relatively mild" electrical abnormalities. The significance of these findings in a minority of patients, who are often already wheelchair-bound, remains obscure.

As the disease progresses, the pyramidal, cerebellar, and speech deficits outlined above often appear gradually. The spouse may report excessive snoring or respiratory stridor, first during sleep and later also during the day. Occasional involuntary inspiratory sighs may also occur. Tracheostomy is sometimes indicated, but in very advanced MSA this is a difficult ethical decision.

Regardless of how the condition starts, the clinical picture of most patients with MSA converges in the advanced stages towards a "full house". In the fully developed disease they are permanently chair- or bedbound, often with an indwelling catheter because they can no longer intermittently self-catheterise, almost mute and severely dysphagic, yet with retained intellect and awareness. Of 19 patients with MSA from the UK Parkinson's Disease Society Brain Bank for whom cause of death was noted at autopsy, 15 died of bronchopneumonia.

Survival from first symptom to death is variable, but the disease significantly shortens life. Among 217 pathologically confirmed cases described in published reports before 1990, median survival, as judged from the case reports, was only 5.5 (range 1-14) years. Median survival of 35 cases in the UK Brain Bank was $7 \cdot 3$ (2-15) years, however, and in our own series of 100 prospectively followed patients, is $9.5(1.5-20)$ years. One pathologically proven patient in our series died after 15 years of disease, and one of Rajput et $a l^{39}$ after more than 18 years.

The challenge now is to understand the cause and to develop an effective treatment for this miserable illness.

NIALI P QUINN

C DAVID MARSDEN

Institute of Neurology,

National Hospital for Neurology and Neurosurgery,

Queen Square, London WC1N 3BG, UK

1 Graham JG, Oppenheimer DR. Orthostatic hypotension and nicotine sensitivity in a case of multiple system atrophy. $f$ Neurol Neurosurg Psychiatry 1969;32:28-34.

2 Bannister R, Oppenheimer DR. Degenerative diseases of the nervous system associated with autonomic failure. Brain 1972;95:457-74.

3 Bradbury S, Eggleston C. Postural hypotension. A report of three cases. Am Heart F 1925;1:73-86. 
4 Shy GM, Drager GA. A neurologic syndrome associated with orthostatic hypotension. Arch Neurol 1960;2:511-27.

5 Dejerine J, Thomas AA. L'atrophie olivo-ponto-cérébelleuse. Nouv Iconogr Salpêtrière 1990;13:330-70.

6 Adams RA, van Bogaert L, van der Eecken H. Striato-nigral degeneration. $\mathcal{F}$ Neuropathol Exp Neurol 1964;23:584-608.

7 Oppenheimer D. Neuropathology of progressive autonomic failure. In: Bannister R, ed. Autonomic failure. A textbook of clinical disorders of the autonomic nervous system. Oxford: Oxford University Press, 1983: 267-83.

8 Gray F, Vincent D, Hauw JJ. Quantitative study of lateral horn cells in 15 cases of multiple system atrophy. Acta Neuropathol 1988;75:513-8.

9 Berciano J. Olivopontocerebellar atrophy. A review of 117 cases. $\mathcal{F}$ Neurol Sci 1982;53:253-72.

10 Wadia NH. A variety of olivopontocerebellar atrophy distinguished by slow eye movements and peripheral neuropathy. Adv Neurol 1984;41: 149-77.

11 Papp MI, Kahn JE, Lantos PL. Glial cytoplasmic inclusions in the CNS of patients with multiple system atrophy (striatonigral degeneration, olivopontocerebellar atrophy and Shy-Drager syndrome). $\mathcal{f} \mathrm{Neurol} S \mathrm{Sci}$ 1989;94:79-100.

12 Nakazato Y, Yamazaki $H$, Hirato J, Ishida Y, Yamaguchi $H$. Oligodendroglial microtubular tangles in olivopontocerebellar atrophy. f Neuropathol Exp Neurol 1990;49:521-30.

13 Kato S, Nakamura H, Hirano A, Ito H, Llena JF, Yen S-H. Argyrophilic ubiquitinated cytoplasmic inclusions in Leu-7-positive glial cells in olivopontocerebellar atrophy (multiple system atrophy). Acta olivopontocerebellar atrophy

14 Mochizuki A, Mizusawa H, Ohkoshi N, et al. Argentophilic intracytoplasmic inclusions in multiple system atrophy. F Neurol 1992;239:311-6.

15 Costa C, Duyckaerts C, Cervera P, Hauw J-J. Les inclusions oligodendrogliales, un marqueur des atrophies multisystématisées. Rev Neurol 1992;148:274-80.

16 Kato $\mathrm{S}$, Nakamura $\mathrm{H}$. Cytoplasmic argyrophilic inclusions in neurons of pontine nuclei in patients with olivopontocerebellar atrophy: immunohistochemical and ultrastructural studies. Acta Neuropathol 1990;79: 584-94.

17 Papp MI, Lantos PL. Accumulation of tubular structures in oligodendroglial and neuronal cells as the basic alteration in multiple system atrophy. 7 Neurol $S c i$ 1992;107:172-82.

18 Quinn N. Multiple system atrophy-the nature of the beast. 7 Neurol Neurosurg Psychiatry 1989;52:Special Suppl 78-89.

19 Quinn N. Multiple system atrophy. In: Marsden CD, Fahn S, eds. Quinn N. Multiple system atrophy. In: Marsden CD, Fahn
Movement disorders 3. London: Butterworth-Heinemann, in press.

20 Quinn N, Daniel S, Magalhães-Branco M, Lees A, Hughes A. Lack of pyramidal tract signs in Parkinson's disease. Lancet 1992;ii: 125.

21 Brooks DJ, Ibanez V, Sawle GV, et al. Striatal $\mathrm{D}_{2}$ receptor status in patients with Parkinson's disease, striatonigral degeneration, and progressive supranuclear palsy, measured with ${ }^{11} \mathrm{C}$-raclopride and positron emission tomography. Ann Neurol 1992;31:184-92.
22 Burn DJ, Mathias CJ, Quinn N, Marsden CD, Brooks DJ. Striatal opiate receptor binding in Parkinson's disease and multiple system atrophy: "C-diprenorphine study. Neurology 1993;43(Suppl 2),A270.

23 Rascol O, Sabatini U, Simonetta-Moreau M, Montastruc J-L, Rascol A, Clanet M. Square wave jerks in parkinsonian syndromes. $\mathcal{f}$ Neurol Neurosurg Psychiatry 1991;54:599-602.

24 Duvoisin RC, Yahr MD, Lieberman J, Antunes J, Rhee S. The striatal foot. Trans Am Med Assoc 1972;97:267.

25 Nausieda PA, Weiner WJ, Klawans HL. Dystonic foot response of parkinsonism. Arch Neurol 1980;37:132-6.

26 Polinsky RJ, Nee LE. Autonomic failure: Nosology, clinical evaluation and prognosis. Ann Neurol 1989;26:121.

27 Obeso JA, Rodriguez ME, Artieda J, et al. Focal reflex myoclonus: A useful sign in the differential diagnosis of parkinsonism. Ann Neurol 1989;26:164-5.

28 Robbins TW, James M, Lange KW, Owen AM, Quinn NP, Marsden CD. Cognitive performance in multiple system atrophy. Brain 1992; 115:271-91.

29 Lees AJ. The treatment of multiple system atrophy. In: Bannister R, Mathias C, eds. Autonomic failure, 3rd edn. Oxford: Oxford University Press, 1992:646-55.

30 Hughes AJ, Colosimo C, Kleedorfer B, Daniel SE, Lees AJ. The dopaminergic response in multiple system atrophy. 7 Neurol Neurosur Psychiatry 1992;55:1009-13.

31 Hughes AJ, Lees AJ, Stern GM. Challenge tests to predict the dopaminergic response in untreated Parkinson's disease. Neurology 1991;41: 1723-5.

32 Schwarz J, Tatsch K, Arnold G, et al. 123 I-iodobenzamide-SPECT predicts dopaminergic responsiveness in patients with de novo parkin predicts dopaminergic responsiven

33 Olanow CW, Alberts M, Djang W, Stajich J. MR imaging of putamenal iron predicts response to dopaminergic therapy in parkinsonian patients. In: Dostert P, Riederer P, Strolin Benedetti M, Roncucci R, eds. Early markers in Parkinson's and Alzheimer's diseases. Vienna: Springer-Verlag, 1990:99-109.

34 Eardley I, Quinn NP, Fowler CJ, et al. The value of urethral sphincter electromyography in the differential diagnosis of parkinsonism. $\mathrm{Br} f$ Urol 1989;64:360-2.

35 Quinn NP. Unilateral facial dystonia in multiple system atrophy. Mov Disord 1992;7:Suppl 1, 79.

36 Rivest J, Quinn N, Marsden CD. Dystonia in Parkinson's disease, multiple system atrophy, and progressive supranuclear palsy. Neurology 1990 40:1571-8.

37 Quinn N. Disproportionate antecollis in multiple system atrophy. Lancet

38 Cohen J, Low P, Fealey R, Sheps S, Jiang N-S. Somatic and autonomic function in progressive autonomic failure and multiple system atrophy Ann Neurol 1987;22:692-9.

39 Rajput AH, Rozdilsky B, Rajput A. Accuracy of clinical diagnosis in parkinsonism-A prospective study. Can f Neurol Sci 1991;18:275-8.

\section{Neurological stamp}

\section{Anders Celsius (1701-1744)}

Celsius, Professor of Astronomy in his native town of Uppsala, Sweden, from 1730 to 1744 , devised a temperature scale in 1742 . The temperature of melting ice was taken as $100^{\circ}$ and the temperature of boiling water to be $0^{\circ}$. A colleague, Martin Stromer, inverted the scale eight years later. The modern celsius (or centigrade) has opposite fixed points (freezing $0^{\circ}$, boiling $100^{\circ}$ ). The word centigrade (centum $=100$, gradus $=$ step) describes the scale, but ignores the name of the inventor of this widely used clinical instrument. This stamp was issued by Sweden in 1982 (Stanley Gibbons 1111; Scott 1402).

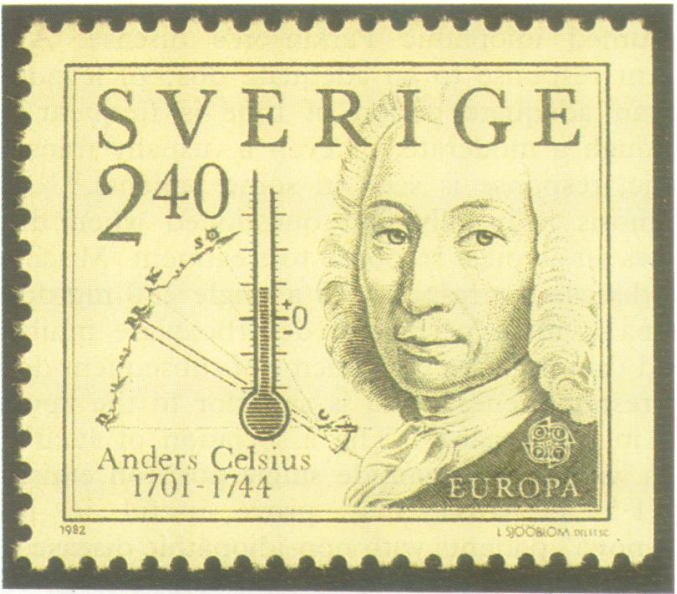


problems in elderly patients.

The scope is wide, including sleep disorders, thermoregulation, pain, depression, visual and hearing difficulties, the problems of family supporters and living wills. Those common but poorly understood neurological problems such as cramp, neck pain and incontinence are dealt with honestly. The chapter on how to interview patients is excellent, though the central importance of the telephone in history taking is overlooked. I would have liked more detail on the physical examination, especially on how to observe an older person standing, walking, turning and sitting-assessments often missing from medical case notes. The emphasis on foot problems and footwear is a welcome inclusion.

The book is liberally illustrated with MRI pictures. There are copious up-to-date references, from Europe as well as North America. The writing style is lucid and the many contributors give down-to-earth advice based on published data. In many cases, we have no facts to help direct our treatment; where there is ignorance or controversy, sensible guidelines are offered.

There are important gaps: agnosia and apraxia are overlooked and visual hallucinations are poorly covered. The elderly driver get only a few lines. There is relatively little on rehabilitation. I was surprised to find benzodiazepines being recommended as sedatives for old people.

But this book looks and feels good, reads well and gives an informed positive account of geriatric neurology. I will refer to it often and will urge my junior colleagues to do the same.

GRAHAM MULLEY

The Brain: A Neuroscience Primer 2nd Edition. By RICHARD F THOMPSON. 1993. (Pp 496 Illustrated; Price: $£ 25.95$ board, £18.95 paper). Oxford, WH Freeman \& Co. Ltd. ISBN Board 0-7167-2338-7, Paper 0-7167-2485-5.

This book aims to introduce someone with no background knowledge or prior exposure to the field to the basics of neuroscience and the biological aspects of psychology.

It is set out in a logical way. After an introductory chapter giving an overview of the nervous system there are chapters on the neuron, membranes and potentials, synaptic transmission and neurotransmitters and hormones. These are followed by consideration at a higher level: chapters on the hypothalamus and biological imperatives, then sensory and motor systems. Chapters follow on development and plasticity of the brain, chapters on learning and memory and finally language and consciousness. This is accompanied by an excellent glossary and an appendix reassuringly entitled 'A tiny bit of chemistry, physics, and pharmacology'. Each chapter is followed by a clear concise summary and a series of suggested readings and references.

Dr Thompson's style is easy to read. $\mathrm{He}$ conveys difficult ideas in a straightforward way and manages to avoid frequent abbreviations which often muddy technical writing. In introducing a subject he sets the historical context by describing how discoveries were made, particularly, it seems, those that led to Nobel prizes. Classical experiments, such as Hodgkin and Huxley's work with squid axon and Pavlov's work with conditioning, are described. The descriptions of the current state of knowledge that follows are also punctuated with references to interesting experiments. The reader is left in no doubt that this is an advancing science. There are frequent illustrations (well over 100) that complement the text, and a few excellent cartoons. This excellent book should be on the reading list of every preclinical neuroscience course.

GN FULLER

\section{SHORT NOTICES}

New Functional Aspects of the Suprachiasmatic Nucleus of the Hypothalamus. (International Symposium, Osaka, Japan, October 1991). Edited by $\mathrm{H}$. NAKAGAWA, Y OOMURA AND $K$ NAGAI. (Pp 264; Price: $£ 330.00$, US $\$ 60)$. London: John Libbey \& Co. Ltd. 1993. 1993. ISBN 0861963296 .

Parkinson's Disease: Symposium Review 1992. Edited by MERTON SANDLER. (Pp 65; Price: $£ 12.00$, US\$24). London: John Libbey \& Co. Ltd. 1993. ISBN 0861964047 .

This volume comprises papers presented at the Morbus Parkinson Symposium, Maastricht, January 1992, and the Satellite Symposium "The existing role of dopamine agonists: the search for new strategies", Munich, June 1992

A useful practical review of current treatment.

Teamwork in Neurology. (Therapy in Practice Series/40). By RUTH NEUWENHUIS. (Pp 198; Price: £13.95). 1993. London: Chapman \& Hall. ISBN 0-412-39350-6.

The Neuropsychology of Attention (Series: Critical Issues in Neuropsychology). By RONALd A COHEN. (Pp 545; Price: $\$ 90.00 \mathrm{H} / \mathrm{bk}) .1993$. New York, Plenum Publishing Corp. ISBN 0-30643953-0

Neurology Secrets. Edited by LOREN A ROLAK. (Pp 432; Price: \$36.95). 1993. Philadelphia, Hanley \& Belfus Inc. ISBN 0-56053-056-

Electrical and Magnetic Stimulation of the Brain and Spinal Cord (Advances in Neurology, Vol. 63). Edited by O DEVINSKY, A BERIC AND MICHAEL DOGALI (Pp 323; Price: \$139.00) 1993. New York, Raven Press. ISBN 0-7817-0066-3.

Anatomic Localization for Needle Electromyography. By STEVE R GEIRINGER (Pp 154 Illustrated; Price: \$28.95) 1994. Philadelphia, Hanley \& Belfus Inc. ISBN 1 560530685 .
Neurosurgery for the Third Millennium (Series: Neurosurgical Topics/11). Edited by MICHAEL LJ APUZZO, AANS Publications Committee. (Pp 209 Illustrated; Price $\$ 80$ for AANS members, $\$ 90$ for non-members, $\$ 70$ for AANS residents). 1992 Park Ridge, Illinois. The American Association of Neurological Surgeons ISBN 1-879284-08-1

Neurosurgery-The Scientific Basis of Clinical Practice (2 vols). Edited by A CROCKARD, R HAYWARD AND TT HOFF. (Vol.1 pp. 1-512, Vol.2 pp. 513-994; Price £195.00). 1992. Oxford, Blackwell Scientific Publications Ltd ISBN 0-86542186-2 (The Set) 0-86542-235-4 (Vol. 1) P-86542-236-2 (Vol. 2).

The Mental Status Examination in Neurology/Third Edition. By RL STRUB AND FW BLACK. (Pp 244; Price: $£ 19.95$ ). 1993 Philadelphia, FA Davis Co. UK Distrib: Waverley Europe Ltd, London. ISBN 0-8036-8212-3.

The 3rd edition of this useful source of information and references. It includes valuable standardised items compared to data from formal neuropsychological tests, and age-related data. There. is a selective discussion of the methods and appraisal of cortical function.

Metabolic Brain Dysfunction in Systemic Disorders. Edited by AI ARIEFF AND RC GRIGGs. (Pp 477 Illustrated; Price f80.00). 1992. A Little, Brown Medical Title UK Distrib: Edinburgh. Churchill Livingstone ISBN 0-316-05067-9.

Spinal Dysraphism (Series: Contemporary Issues in Neurological Surgery). Edited by TS PARK (Pp 190 Illustrated; Price: $£ 49 \cdot 50)$. 1992. Oxford, Blackwell Scientific Publications ISBN 0-86542-105-6.

CORRECTIONS

Anderson, Milne. The motor disorder of multiple system atrophy. $\mathcal{f}$ Neurol Neurosurg Psychiatry 1993;56:1239-42 (editorial). The dosage of dexamethasone should be $0.15 \mathrm{mg} / \mathrm{kg}$ body weight every six hours for four days.

A note on heterochromia iridis. $\mathcal{f}$ Neurol Neurosurg Psychiatry 1993;57:231. This short article should have been attributed to Dr Patrick J Morrison, Northern Ireland Genetics Service, Belfast City - Hospital, Belfast BT9 7AB, UK. 